Article

\title{
Isothiocyanate-Functionalized Mesoporous Silica Nanoparticles as Building Blocks for the Design of Nanovehicles with Optimized Drug Release Profile
}

\author{
Gabriel Martínez-Edo ${ }^{1}$, Maria C. Llinàs ${ }^{1}$, Salvador Borrós ${ }^{1,2}$ (D) and David Sánchez-García ${ }^{1, *(1)}$ \\ 1 Grup d'Enginyeria de Materials (GEMAT), Institut Químic de Sarrià, Universitat Ramon Llull, Via Augusta, \\ 390, 08017 Barcelona, Spain \\ 2 Centro de Investigación Biomédica en Red en Bioingeniería, Biomateriales y Nanomedicina (CIBER-BBN), \\ 50018 Zaragoza, Spain \\ * Correspondence: david.sanchez@iqs.url.edu; Tel.: +34-932-672-122
}

Received: 23 July 2019; Accepted: 22 August 2019; Published: 29 August 2019

\begin{abstract}
A straightforward methodology for the synthesis of isothiocyanate-functionalized mesoporous silica nanoparticles (MSNs) by exposure of aminated MSNs to 1,1'-thiocarbonyldi$2(1 H)$-pyridone is reported. These nanoparticles are chemically stable, water tolerant, and readily react with primary amines without the formation of any by-product. This feature allows the easy modification of the surface of the nanoparticles for tuning their physical properties and the introduction of gatekeepers on the pore outlets. As a proof-of-concept, amino-isothiocyanate-functionalized MSNs have been used for the design of a nanocontainer able to release the drug Ataluren. The release profile of the drug can be easily fine-tuned with the careful choice of the capping amine.
\end{abstract}

Keywords: mesoporous silica nanoparticles; regioselective functionalization; drug delivery; isothiocyanate

\section{Introduction}

Mesoporous silica nanoparticles (MSNs) are currently of great interest in biomedicine owing to their potential as building blocks for the design of multifunctional systems for drug delivery [1-5], and bioimaging [6,7]. To a great extent, the versatility of MSNs is due to their singular geometry, which is characterized by the presence of two distinct domains: The internal mesoporous area and an external surface. While the internal mesopores of the MSNs provide a large volume area for the loading of drugs, the outer surface allows their functionalization with valves [8], ligands [9], or probes [10].

In order to attain the level of complexity needed for the design of "smart" nanocarriers, it is necessary to develop efficient methods for the selective functionalization [11,12] of the two surfaces of the MSNs. The coating of the porous surface with the proper functional group (e.g., amines [13-16], hydrazones [17]) is crucial for the optimization of the drug loading. Regarding the external surface, this domain is suitable to install stimulus-responsive systems for drug release [18] or attach functionality for cell targeting [19]. From a chemical perspective, the preparation of such complex systems requires clean (free of by-products) and optimized (general) methodologies [20,21]. Hence, the ideal building block for the preparation of MSNs-based carriers should be (i) orthogonally bifunctionalized, (ii) easy to prepare and purify, and (iii) chemically stable and storable.

A reliable methodology to prepare such bifunctional MSNs in a regioselective fashion consists in the derivatization of the outer surface of mono-functionalized MSNs with the pores blocked by the surfactant [22-24]. In this context, aminated MSNs emerge as an ideal starting material given the rich chemistry of the amino moiety, which can be easily derivatized by nucleophilic or acyl substitution $[25,26]$. Owing to their versatility, aminated MSNs have been studied in great detail, 
and the available synthetic protocols based on the co-condensation methodology allow the fine-tuning of their morphology [27,28] and the localization of the amino groups [29]. Thus, the synthetic problem is reduced to the choice of a proper reactive group for the outer surface of the MSNs [30,31]. Typically, MSNs are functionalized using long and tedious procedures requiring the treatment of the particles with a functionalized trialkoxysilane (e.g., 3-aminopropyltrimethoxysilane (APTMS), 3-mercaptopropyltrimethoxysilane (MPTMS)) in refluxing toluene. Afterward, this material can be properly derivatized with the aid of amidation protocols [32,33], the thiol-yne coupling [34], or the $\mathrm{Cu}(\mathrm{I})$-catalyzed azide-alkyne cycloaddition (CuAAC) [35].

Herein, we report the development of ready-to-use isothiocyanate MSNs, which can be prepared by simple exposure of aminated MSN to a "thiocarbonyl transfer reagent". The isothiocyanate moiety readily reacts with primary amines to yield thioureas and is compatible with aqueous media. The coupling between isothiocyanates and amines does not require any activating agent or transition metal catalyst [36], which must be carefully removed from the nanoparticles prior to any biological test [37]. In terms of reactivity, the isothiocyanate group is comparable to the isocyanate [38,39], however, the former is not prone to hydrolysis [40]. Hence, it is stable in aqueous media and can be stored [41]. Interestingly, although isothiocyanates are well known as reactive groups in bioconjugation chemistry [42], to the best of our knowledge, isothiocyanate-functionalized nanoparticles have been scarcely described in the literature [43]. In this paper, the efficiency of this new procedure will be assessed and compared with the CuAAC protocol. Furthermore, this methodology will be applied to the synthesis of amino-isothiocyanate MSNs. These nanoparticles will be used for the encapsulation of a model drug (Ataluren). The preparation of such a nanovehicle and the fine tuning of the release of the drug will be discussed.

\section{Materials and Methods}

\subsection{Materials}

Cetyltrimethylammonium bromide (CTAB), tetraethylorthosilicate (TEOS), 3-aminopropyl triethoxysilane (APTES), dry toluene, absolute ethanol, methanol, acetonitrile (ACN), anhydrous dichloromethane (DCM), ethyl acetate (EtOAc), and tetraethylene glycol monomethyl ether were purchased from ACROS; ammonium hydroxide $\left(\mathrm{NH}_{4} \mathrm{OH}\right)$ from Fluka (St. Louis, Missouri, USA); 1,1'-thiocarbonyldi-2(1H)-pyridone, (2-aminoethyl)trimethylammonium chloride hydrochloride, hydrochloric acid $(\mathrm{HCl})$, trifluoroacetic acid (TFA), sodium bicarbonate $\left(\mathrm{NaHCO}_{3}\right)$, magnesium sulfate $\left(\mathrm{MgSO}_{4}\right)$, copper iodide (CuI), N,N-diisopropylethylamine (DIPEA), sodium diethyldithiocarbamate, ammonium nitrate $\left(\mathrm{NH}_{4} \mathrm{NO}_{3}\right)$, potassium carbonate $\left(\mathrm{K}_{2} \mathrm{CO}_{3}\right)$, cystamine dihydrochloride, Ataluren, citric acid, sodium phosphate $\left(\mathrm{Na}_{2} \mathrm{HPO}_{4} \cdot 12 \mathrm{H}_{2} \mathrm{O}\right)$, 3-bromopropionic acid, 2,5,8,11,14,17,20,23,26, 29,32,35,38,41,44,47-hexadecaoxanonatetracontan-49-ol, fluorescein-5-isothiocyanate (FITC), and 1,8-bromonaphthalimide from Sigma Aldrich (St. Louis, MO, USA). All the chemicals were used as received without further purification.

\subsection{Synthesis of Amino MSNs with CTAB (MSN-NH 2 (CTAB))}

MSN- $\mathrm{NH}_{2}(\mathrm{CTAB})$ were prepared according to the procedure reported in literature [44]. The synthetic procedure was as follows: firstly, $0.2 \mathrm{~g}$ of CTAB were dissolved in $100 \mathrm{~mL}$ of $0.2 \mathrm{M}$ $\mathrm{NH}_{4} \mathrm{OH}$ at $60^{\circ} \mathrm{C}$, and $1.6 \mathrm{~mL}$ of $0.2 \mathrm{M}$ dilute TEOS (in absolute ethanol) was added with vigorous stirring. After the solution was stirred for $5 \mathrm{~h}, 1.6 \mathrm{~mL}$ of $12 \%(\mathrm{v} / \mathrm{v})$ APTES (in absolute ethanol) and $1.6 \mathrm{~mL}$ of $1.0 \mathrm{M}$ TEOS (in absolute ethanol) were added, followed by vigorous stirring for another $1 \mathrm{~h}$. The solution was then aged at $60^{\circ} \mathrm{C}$ for $24 \mathrm{~h}$. Solid samples were collected by centrifugation at 13,000 rpm for $13 \mathrm{~min}$, and then MSNs were washed and dispersed only with deionized water in order to avoid CTAB elimination. 


\subsection{Preparation of Amino MSNs without CTAB $\left(\mathrm{MSN}-\left(\mathrm{NH}_{2}\right)\right)$}

Surfactant templates were removed by extraction in acidic methanol $(0.17 \mathrm{~g}$ of concentrated $\mathrm{HCl}$ in $9 \mathrm{~mL}$ of absolute methanol) for $24 \mathrm{~h}$. Complete removal of the surfactant was checked by FTIR by inspection of the disappearance of bands at 2900 and $2800 \mathrm{~cm}^{-1}$.

The total quantity of amino groups was estimated as follows. To a solution of $10 \mathrm{mg}$ of MSN-( $\left.\mathrm{NH}_{2}\right)$ (CTAB) in $10 \mathrm{~mL}$ of dry toluene, $10 \mathrm{mg}$ of FTIC were added. This solution was stirred for $24 \mathrm{~h}$ at $23^{\circ} \mathrm{C}$. Solid samples were collected by centrifugation at 13,000 rpm for $13 \mathrm{~min}$ and the supernatant was measured at $495 \mathrm{~nm}$ to determine the quantity of unreacted FTIC. The difference with the total amount of FITC added gave the amino groups present on the external surface of MSN-( $\left.\mathrm{NH}_{2}\right)(\mathrm{CTAB})$. The same procedure was repeated with $\mathrm{MSN}-\left(\mathrm{NH}_{2}\right)$, without the surfactant, to determine the total amount of amino groups present on the inner and outer surface. Therefore, in total, there were approximately $8 \times 10^{-7} \mathrm{NH}_{2} \mathrm{~mol} / \mathrm{mg}$ MSN, from which $6 \times 10^{-7} \mathrm{NH}_{2} \mathrm{~mol} / \mathrm{mg} \mathrm{MSN}$ was present on the inner surface of the MSN.

\subsection{Synthesis of Isothiocyanate MSNs (MSN-(NCS))}

Nanoparticles without CTAB (MSN-( $\left.\mathrm{NH}_{2}\right)$ ) were treated with $30 \mathrm{~mL}$ of dry toluene at $50{ }^{\circ} \mathrm{C}$ for $24 \mathrm{~h}$. Forty milligrams of the resulting MSN- $\left(\mathrm{NH}_{2}\right)$ were suspended in $35 \mathrm{~mL}$ of dry toluene and $95 \mathrm{mg}$ of thiocarbonyldi-2(1H)-pyridone (1) $(0.409 \mathrm{mmol}, 12 \mathrm{eq}$.) were added. The suspension was stirred for $24 \mathrm{~h}$ at room temperature. Solid samples were collected by centrifugation at 13,000 rpm for $13 \mathrm{~min}$ and then MSNs were washed and dispersed with $10 \mathrm{~mL}$ of dry toluene and $10 \mathrm{~mL}$ of absolute EtOH. This procedure was repeated six times and, finally, the solvent was evaporated under reduced pressure and MSN-(NCS) were stored dry.

\subsection{Functionalization of MSN-(NCS) with 4-(n-Butylamino)-N-(2-Aminoethyl)-1,8-Naphthalimide (MSN-(UNaph))}

Twenty milligrams of MSN-(NCS) were suspended in $15 \mathrm{~mL}$ of absolute EtOH. Then $6.6 \mathrm{mg}$ of 4-n-butylamino- $N$-(2-aminoethyl)-1,8-naphthalimide (2) $(0.021 \mathrm{mmol}, 2 \mathrm{eq}$.) were added [45]. The mixture was stirred in the dark for $48 \mathrm{~h}$ at room temperature. Solid samples were collected by centrifugation at $13000 \mathrm{rpm}$ for $13 \mathrm{~min}$ and washed and dispersed in absolute EtOH until the disappearance of yellow color (five times, confirmed by tlc of the supernatant).

\subsection{Synthesis of Azido MSNs (MSN- $\left(N_{3}\right)$ )}

Forty milligrams of the resulting MSN- $\left(\mathrm{NH}_{2}\right)$ were suspended in $20 \mathrm{~mL}$ of absolute EtOH. Afterward, $86 \mathrm{mg}$ ( $0.405 \mathrm{mmol}, 12$ eq.) of 3-azidopropionic acid succinimidyl ester (3) in $15 \mathrm{~mL}$ of absolute EtOH were added to the MSN suspension [46]. The mixture was stirred for $24 \mathrm{~h}$ at room temperature. Solid samples were collected by centrifugation at 13,000 rpm for $13 \mathrm{~min}$, and washed and dispersed with EtOH six times. The solvent was evaporated under reduced pressure to give MSN- $\left(\mathrm{N}_{3}\right)$.

\subsection{Functionalization of (MSN-( $\left.N_{3}\right)$ ) with 4-(n-Butylamino)-N-(2-Propargyl)-1,8-Naphthalimide (MSN-(TNaph))}

Twenty-six milligrams of MSN- $\left(\mathrm{N}_{3}\right)$ were suspended in $20 \mathrm{~mL}$ of $\mathrm{ACN}$. Then $7.7 \mathrm{mg}$ of 4-(n-butylamino)- $N$-(2-propargyl)-1,8-naphthalimide (4) ( $0.025 \mathrm{mmol}, 2 \mathrm{eq}$.) with $3 \mathrm{mg} \mathrm{CuI} \mathrm{(0.001} \mathrm{mmol)}$ and three drops of DIPEA were added [47]. The mixture was stirred for $48 \mathrm{~h}$ at room temperature in the dark. Solid samples were collected by centrifugation at 13,000 rpm for $13 \mathrm{~min}$ and washed with diethyldithiocarbamate until the yellow color disappeared. Twelve washings were needed in order to remove the $\mathrm{Cu}$-diethyldithiocarbamate complex (monitored by UV-vis at $730 \mathrm{~nm}$ ) [35,37]. Afterward, MSNs were suspended in a methanolic solution of $\mathrm{HCl} 0.1 \mathrm{M} / \mathrm{MeOH}$ for $12 \mathrm{~h}$. Finally, solid samples were collected by centrifugation and washed and dispersed in $\mathrm{EtOH}$. 


\subsection{Synthesis of Bifunctionalized Amino-Isothiocyanate $\mathrm{MSNs}\left(\mathrm{MSN}-\left(\mathrm{NH}_{2}\right)_{i}(\mathrm{NCS})_{0}\right)$}

Forty-four milligrams of $\mathrm{MSN}-\mathrm{NH}_{2}(\mathrm{CTAB})$ were dissolved in $20 \mathrm{~mL}$ of dry toluene and stirred at $50{ }^{\circ} \mathrm{C}$ for $24 \mathrm{~h}$. Then, $42 \mathrm{mg}$ of thiocarbonyldi-2(1H)-pyridone (1) $(0.180 \mathrm{mmol}, 20$ eq. $)$ were added and the mixture was stirred at room temperature for $24 \mathrm{~h}$. Solid samples were collected by centrifugation at 13,000 rpm for $13 \mathrm{~min}$ and then washed with absolute EtOH twice. Then, the tensioactive component was eliminated by adding to the dispersion $30 \mathrm{~mL}$ of a $0.1 \mathrm{M} \mathrm{NH}_{4} \mathrm{NO}_{3}$ methanolic solution for $24 \mathrm{~h}$. Solid samples were collected by centrifugation and then washed and dispersed with absolute EtOH and water. The solvent was evaporated under reduced pressure and the resulting $\mathrm{MSN}-\left(\mathrm{NH}_{2}\right)_{\mathrm{i}}\left(\mathrm{NCS}_{\mathrm{O}}\right.$ were stored dry.

\subsection{Ataluren Loading in $\left.\mathrm{MSN}-\left(\mathrm{NH}_{2}\right)_{i}(\mathrm{NCS})_{0}\right)$}

One hundred milligrams of MSN-( $\left.\mathrm{NH}_{2}\right)_{\mathrm{i}}(\mathrm{NCS})_{\mathrm{o}}$ were dissolved in $75 \mathrm{~mL}$ of absolute ethanol and stirred vigorously at room temperature for $1 \mathrm{~h} 30 \mathrm{~min}$. Then, $67 \mathrm{mg}$ of Ataluren (5) (0.236 mmol) were added and the mixture was stirred at room temperature for $24 \mathrm{~h}$. Finally, solid samples were collected by centrifugation at 13,000 rpm for $13 \mathrm{~min}$. Nanoparticles were washed with ethanol once.

\subsection{Synthesis of Tert-Butyl(2-((2-Isothiocyanatoethyl)Disulfanyl)Ethyl)Carbamate (6)}

$0.79 \mathrm{~g}$ (3.11 mmol) of tert-butyl(2-((2-aminoethyl)disulfanyl)ethyl)carbamate synthesized from cystamine dihydrochloride [48] and $0.68 \mathrm{~g}$ (2.95 mmol) of 1,1'-thiocarbonylbis(pyridine-2(1H)-one) (1) were dissolved in $50 \mathrm{~mL}$ of anhydrous DCM. The reaction was stirred at $25^{\circ} \mathrm{C}$ for $24 \mathrm{~h}$. Then, the organic phase was washed with $\mathrm{H}_{2} \mathrm{O}$ and $\mathrm{NaHCO}_{3}$ twice. Afterwards, the organic layer was dried over $\mathrm{MgSO}_{4}$ and then the solution was evaporated. Yield: $0.057 \mathrm{~g}(\eta=5.7 \%)$.

${ }^{1} \mathrm{H}$ NMR $\left(400 \mathrm{MHz}, \mathrm{CDCl}_{3}\right) \delta 4.85(\mathrm{~s}, 1 \mathrm{H}), 3.84(\mathrm{t}, J=6.6 \mathrm{~Hz}, 2 \mathrm{H}), 3.46(\mathrm{q}, J=6.3 \mathrm{~Hz}, 2 \mathrm{H}), 2.94(\mathrm{t}$, $J=6.6 \mathrm{~Hz}, 2 \mathrm{H}), 2.82(\mathrm{t}, J=6.4 \mathrm{~Hz}, 2 \mathrm{H}), 1.45(\mathrm{~s}, 9 \mathrm{H}) .{ }^{13} \mathrm{C}$ NMR $\left(100 \mathrm{MHz}, \mathrm{CDCl}_{3}\right) \delta 155.7,132.8,79.7$, 44.0, 39.3, 38.5, 37.9, 28.4. IR (KBr) $v_{\text {max }}$ : 3354.18, 2976.65, 2929.07, 2187.71, 2113.20, 2082.62, 1699.95, $1509.44 \mathrm{~cm}^{-1}$. Calculated organic elemental analysis (OEA) C: 40.79\%; H: 6.16\%; N: 9.51\%, O: 10.87\%, S: $32.66 \%$. Experimental OEA C: $40.71 \%$; $\mathrm{H}: 6.37 \%$; N $9.31 \%$; S: $32.15 \%$.

\subsection{Synthesis of Tert-Butyl (51-Thioxo-2,5,8,11,14,17,20,23,26,29,32,35,38,41,44,47-Hexadecaoxa- 55,56,Dithia-50,52-Diazaoctapentacontan-58-yl)Carbamate (7)}

$1.73 \mathrm{mmol}$ of $2,5,11,14,17,20,23,26,29,32,35,38,41,44,47$-hexadecaoxanonatetraconta-49-amine synthesized from 2,5,11,14,17,20,23,26,29,32,35,38,41,44,47-hexadecaoxanonatetraconta-49-ol [49] and $562 \mathrm{mg}(1.91 \mathrm{mmol})$ of 6 were dissolved in $50 \mathrm{~mL}$ of anhydrous DCM. The reaction was stirred at $20{ }^{\circ} \mathrm{C}$ for $24 \mathrm{~h}$. The resulting product 7 was purified by silica gel column chromatography using a DCM:ACOEt mixture (50:50). The solvent was removed under vacuum to yield the pure product 7. Yield: $0.236 \mathrm{~g}(\eta=27 \%)$.

${ }^{1} \mathrm{H}-\mathrm{NMR}\left(400 \mathrm{MHz}, \mathrm{CDCl}_{3}\right) \delta 6.94$ (brs, 1H), 5.24 (brs, 1H), 3.90 (brs, 2H), 3.74-355 (overlapping multiplets, 72H), 3.45 (brs, 2H), 3.37 (s, 3H), 2.96 (brs, 2H), 2.78 (brs, 2H), 1.45 (s, 9H). ${ }^{13} \mathrm{C}-\mathbf{N M R}$ $\left(100 \mathrm{MHz}_{\mathrm{CDCl}}\right) \delta 183.2,155.9,79.5,71.8,70.5,70.4,70.2,70.0,58.9,44.0,39.4,37.9,37.8,28.4$. IR (KBr) $v_{\text {max }}: 3517,3335,2871,1709,1542,1454,1107 \mathrm{~cm}^{-1}$ MALDI-TOF Matrix: DHB $10 \mathrm{mg} / \mathrm{mL}$ acetone, Ratio Sample-Matrix-NaTFA: 4:20:2, Method: Reflector positive ion mode (RP_master): 619.916, 692.848, 745.783, 736.931, 758.927, 878.043, 922.075, 965.111, 1009.188, 1053.275, 1053.275, 1097.309, 1141.357, $1185.463,1229.516,1273.535$.

\subsection{Synthesis of 1-(2-((2-Aminoethyl)Disulfanyl)Ethyl)-3-(2,5,8,11,14,1,20,23,26,29,32,35,38,41,44,47- Hexadecaoxanonatetracontan-49-yl)Thiourea (8)}

Ten milliliters of anhydrous DCM were used to dissolve $0.26 \mathrm{mmol}$ of 7 . The mixture was cooled at $0^{\circ} \mathrm{C}$ and stirred for $30 \mathrm{~min}$. Then, $1 \mathrm{~mL}(13 \mathrm{mmol})$ of trifluoroacetic acid (TFA) was added dropwise. 
Afterward, the mixture was stirred for $1.5 \mathrm{~h}$ at $0{ }^{\circ} \mathrm{C}$ and the solvent was removed under vacuum. Compound 8 was used without further purification.

\subsection{Functionalization of $\mathrm{MSN}-\left(\mathrm{NH}_{2}\right)_{i}(\mathrm{NCS})_{0}$ with Aminotetraethylene Glycol Monomethyl Ether and Loading of Ataluren (MSN- $\left(\mathrm{NH}_{2}\right)_{i}(\mathrm{PEG})_{0}$ (Ataluren))}

Twenty-two milligrams of MSN-( $\left.\mathrm{NH}_{2}\right)_{\mathrm{i}}(\mathrm{NCS})_{\mathrm{o}}$ were suspended in $30 \mathrm{~mL}$ of absolute EtOH and stirred vigorously for $1 \mathrm{~h}$. Then, $16 \mathrm{mg}$ of Ataluren (5) $(0.056 \mathrm{mmol})$ were added to the solution. The mixture was stirred at room temperature for $24 \mathrm{~h}$. Afterward, $30 \mathrm{mg}$ (0.144 mmol, $181 \mathrm{eq}$.) of aminotetraethylene glycol monomethyl ether (PEG, 9) was added, and the mixture was stirred for another $24 \mathrm{~h}$ at room temperature [50]. Solid samples were collected by centrifugation at 13,000 rpm for $13 \mathrm{~min}$. Nanoparticles were washed with absolute ethanol twice. The washings were collected and the concentration of Ataluren was determined by UV-vis spectroscopy at $244 \mathrm{~nm}$ to calculate the loading of the drug by difference.

2.14. Functionalization of $\mathrm{MSN}-\left(\mathrm{NH}_{2}\right)_{i}(\mathrm{NCS})_{0}$ with 1-(2-((2-Aminoethyl)Disulfanyl)Ethyl)-3$(2,5,8,11,14,1,20,23,26,29,32,35,38,41,44,47-H e x a d e c a o x a n o n a t e t r a c o n t a n-49-y l)$ Thiourea and Loading of Ataluren $\left(\mathrm{MSN}-\left(\mathrm{NH}_{2}\right)_{i}(\mathrm{SS}-\mathrm{PEG})_{0}\right.$ (Ataluren))

Thirteen milligrams of MSN-( $\left.\mathrm{NH}_{2}\right)_{\mathrm{i}}(\mathrm{NCS})_{\mathrm{o}}$ were dissolved in $30 \mathrm{~mL}$ of absolute EtOH and stirred vigorously for $1 \mathrm{~h}$. Then, $11 \mathrm{mg}$ of Ataluren (5) $(0.0397 \mathrm{mmol})$ were added to the solution. The mixture was stirred at $20^{\circ} \mathrm{C}$ temperature for $24 \mathrm{~h}$. Then, $216 \mathrm{mg}(539.78 \mathrm{mmol})$ of 8 were added to the silica nanoparticles. Finally, the mixture was stirred for another $24 \mathrm{~h}$. Solid samples were collected by centrifugation at 13,000 rpm for $13 \mathrm{~min}$. Nanoparticles were washed with absolute EtOH twice. The washings were collected and the concentration of Ataluren was determined by UV-vis spectroscopy at $244 \mathrm{~nm}$ to calculate the loading of the drug by difference.

\subsection{Functionalization of $\mathrm{MSN}-\left(\mathrm{NH}_{2}\right)_{i}(\mathrm{NCS})_{0}$ with (2-Aminoethyl)Trimethylammonium Chloride Hydrochloride and Loading of Ataluren $\left(\mathrm{MSN}-\left(\mathrm{C}^{+}\right)_{0}\right.$ (Ataluren))}

Sixty milligrams of $\mathrm{MSN}-\left(\mathrm{NH}_{2}\right)_{\mathrm{i}}(\mathrm{NCS})_{\mathrm{o}}$ were suspended in $30 \mathrm{~mL}$ of basic water $\left(\mathrm{K}_{2} \mathrm{CO}_{3}\right.$ $0.2 \mathrm{M}, \mathrm{pH}=8$ ) and stirred vigorously for $1 \mathrm{~h}$. Then, $50 \mathrm{mg}$ of Ataluren (5) (0.176 mmol) were added to the solution. The mixture was stirred at room temperature for $24 \mathrm{~h}$. Then, $7.6 \mathrm{mg}$ of (2-aminoethyl)trimethylammonium chloride hydrochloride (10) (0.0436 mmol, 54.6 eq.) were added, and the mixture was stirred at room temperature for $24 \mathrm{~h}$. Solid samples were collected by centrifugation at 13,000 rpm for $13 \mathrm{~min}$. Nanoparticles were washed with absolute EtOH twice. The washings were collected and the concentration of Ataluren was determined by UV-vis spectroscopy at $244 \mathrm{~nm}$ to calculate the loading of the drug by difference.

\subsection{Release Experiments}

Ten milligrams of MSNs loaded with Ataluren were placed inside an Eppendorf. Then, $1.5 \mathrm{~mL}$ of citric acid $0.1 \mathrm{M} /$ sodium phosphate $\left(\mathrm{Na}_{2} \mathrm{HPO}_{4} \cdot 12 \mathrm{H}_{2} \mathrm{O}\right) 0.2 \mathrm{M}$ buffer $(\mathrm{pH}=7.4)$ was poured into the latter. The Eppendorf was sonicated until a clear dispersion was obtained. After that, the solution was allowed to stand in an incubator for a specified time. The resulting precipitate was isolated by centrifugation at 13,000 rpm for $13 \mathrm{~min}$. In order to calculate the Ataluren concentration through UV-vis spectroscopy at $244 \mathrm{~nm}, 1.3 \mathrm{~mL}$ of the supernatant was extracted and stored. The Eppendorf was refilled again with $1.3 \mathrm{~mL}$ of the previous buffer. All these operations were performed five more times ( $24 \mathrm{~h}$ of release). Ataluren release has been calculated using Equation (S1) (see Supplementary Materials).

\subsection{Characterization}

A high-resolution transmission electron microscope (JEOL JEM 2011, Tokyo, Japan) was used to take micrographs of the MSNs particles. Samples were ultrasonically dispersed in absolute EtOH at a concentration of $0.1 \mathrm{mg} \cdot \mathrm{mL}^{-1}$ and deposited on an amorphous, porous carbon grid. The particle 
size distribution and Z-potential were measured using a Malvern Zetasizer Nano Series ZEN 3600 laser particle size analyzer (Malvern, UK). Samples were prepared at a concentration of $0.1 \mathrm{mg} \cdot \mathrm{mL}^{-1}$ in absolute ethanol for size and $0.05 \mathrm{mg} \cdot \mathrm{mL}^{-1}$ in deionized $\mathrm{H}_{2} \mathrm{O}(\mathrm{pH}=5.5)$ for the Z-potential measurements. Small-angle powder X-ray diffraction (SAXRD) patterns were collected on a Philips $X^{\prime}$ Pert diffractometer (Malvern, UK) equipped with $\mathrm{Cu}-\mathrm{K} \alpha$ radiation (wavelength $1.5406 \AA$ ) in the $2 \theta$ range between $0.6^{\circ}$ and $6.5^{\circ}$ with a step size of $0.02^{\circ}$ and counting time of $5 \mathrm{~s}$ per step. Nitrogen physisorption analysis was conducted on a micromeritics Gemini $V$ surface area and pore size analyzer (Norcross, GA, USA). Samples were treated at $0.05 \mathrm{mBar}$ at $-0.759{ }^{\circ} \mathrm{C}$ approximatively for $16 \mathrm{~h}$ prior to conducting adsorption experiments. The surface area was calculated by the Brunauer-Emmett-Teller (BET) method and the pore size distribution was calculated using the Barrett-Joyner-Halenda (BJH) method. Fourier transform infrared (FTIR) spectra of MSN particles were obtained via a Thermo Scientific, Waltham, MA, USA, Nicolet iS10 FTIR spectrometer with Smart iTr. A EuroVector Instruments, Euro EA elemental analyzer was used for the determination of elemental microanalyses. UV-vis spectra were recorded in a Thermo Scientific 300 UV-vis spectrophotometer. Fluorescence excitation spectra were recorded in a Hitachi F2500, Tokyo, Japan, fluorescence spectrophotometer.

\section{Results and Discussion}

\subsection{Synthesis and Characterization of Isothiocyanate MSNs (MSN-(NCS))}

From a practical point of view, the introduction of the isothiocyanate moiety should take place in one step by direct conversion of the amino groups into the isothiocyanate [51]. A search in the literature reveals that the typical procedure for the preparation of isothiocyanates from amines consists of a two-step methodology [52,53]. An alternative and straightforward protocol is the use of the "thiocarbonyl transfer reagents" [54] such as 1,1'-thiocarbonyldi-2(1H)-pyridone (1). This commercially available reagent reacts smoothly with primary amines under neutral conditions to give high yields of the corresponding isothiocyanate in a single step. The only by-product formed is the water-soluble 2-pyridone [55].

As proof of concept of this chemistry, aminated MSNs (50 and $100 \mathrm{~nm}$ ), prepared following the methodology described by Lo et al. [44], were reacted with 12 eq. of 1,1'-thiocarbonyldi-2(1H)-pyridone (1) in toluene for $24 \mathrm{~h}$ (Figure 1). The resulting MSNs show good chemical stability and can be stored at room temperature indefinitely (checked by reaction of MSN-(NCS) with amine 2).
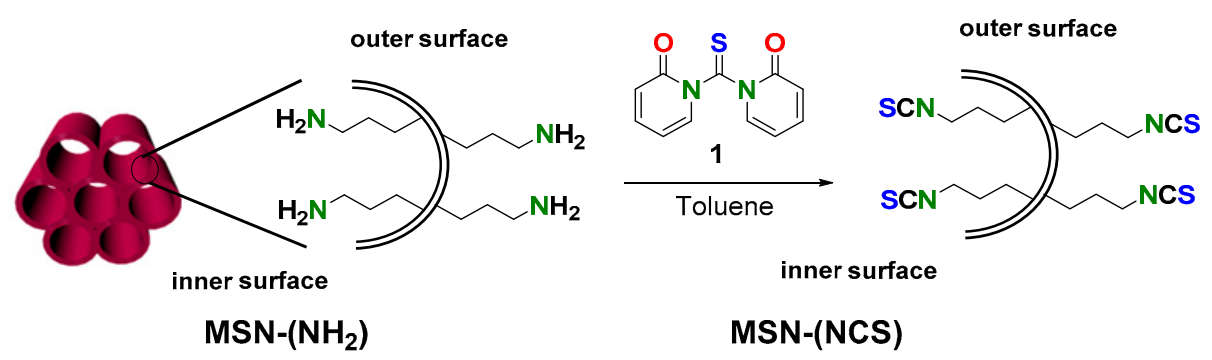

Figure 1. Preparation of mesoporous silica nanoparticle (MSN)-(NCS).

The nanoparticles were characterized by dynamic light scattering (DLS), powder the small-angle X-ray diffraction (SAXRD), TEM, and BET analysis (see Supplementary Materials). As expected, no significant size, shape, and morphology differences were obtained for MSN-(NCS) in comparison with aminated-MSNs. MSN-(NCS) are regular, homogeneous and round shaped. As shown in Figure 2, spherical $100 \mathrm{~nm}$ nanoparticles with typical mesoporous morphology were obtained. The particle size distribution was measured by dynamic light scattering (DLS) as shown in Figure S1 and Table S1 of Supplementary Materials, with the average particle size of $142(\mathrm{pdI}=0.07)$ and $190 \mathrm{~nm}(\mathrm{pdI}=0.19)$ for MSN- $\left(\mathrm{NH}_{2}\right)$ and MSN-(NCS), respectively. Z-potential was also measured. The values recorded were 
-12 and $-11 \mathrm{mV}$ for $100 \mathrm{~nm}$ MSN-( $\left.\mathrm{NH}_{2}\right)$ and MSN-(NCS), respectively (As for the $50 \mathrm{~nm}$ nanoparticles, see Table S1, Figures S1 and S2).
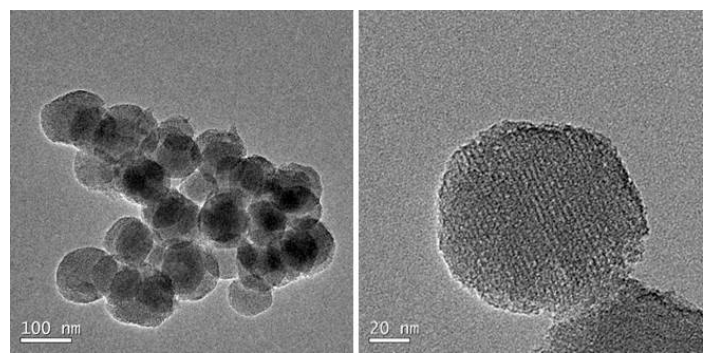

Figure 2. Representative transmission electron microscope (TEM) images of $100 \mathrm{~nm} \mathrm{MSN-(NCS).}$

Powder SAXRD patterns of MSN-(NCS) was also carried out. SAXRD pattern presents highly ordered structures with $\mathrm{d}_{100}$ at 2.3 and lighter faceted hexagon-shape at 4.1 and 4.2 which indicated two-dimensional (2D) long-range ordering structure (Figure 3).

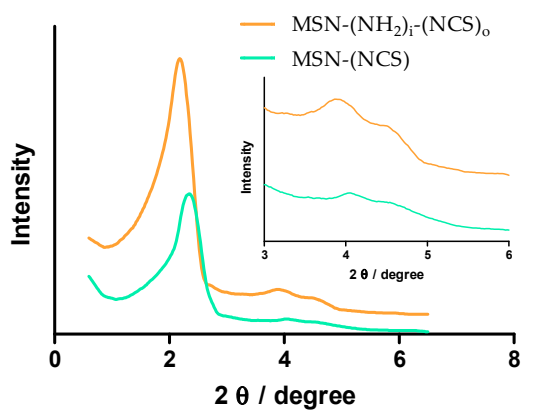

Figure 3. Small-angle X-ray diffraction (SAXRD) of MSN-(NCS) and MSN-( $\left.\mathrm{NH}_{2}\right)_{\mathrm{i}}(\mathrm{NCS})_{\mathrm{o}}(100 \mathrm{~nm})$.

The nitrogen adsorption-desorption technique was used to analyze the surface area, pore volume, and pore size distribution of the MSN-( $\left.\mathrm{NH}_{2}\right)$ and MSN-(NCS) particles. BET isotherm curves of MSN samples (100 nm nanoparticles), as displayed in Figure 4, showed type IV isotherms, which indicate clear H1 hysteresis loop characteristic of mesoporous materials. BET surface areas are over $1120 \mathrm{~m}^{2} \cdot \mathrm{g}^{-1}$ for MSN-( $\left.\mathrm{NH}_{2}\right)$ and $850 \mathrm{~m}^{2} \cdot \mathrm{g}^{-1}$ for MSN-(NCS). Additionally, the pore volume for MSN-(NCS) was $0.53 \mathrm{~cm}^{3} \cdot \mathrm{g}^{-1}$. As a reference, the value recorded for MSN- $\left(\mathrm{NH}_{2}\right)$ was $0.72 \mathrm{~cm}^{3} \cdot \mathrm{g}^{-1}$. These decreases in both the surface area and the pore volume are consistent with the functionalization of the pores of the nanoparticle. The MSN-(NCS) present a very narrow pore size distribution centered at $2.2 \mathrm{~nm}$. These data suggest that the mild conditions used for the functionalization do not erode the structural features of the MSNs (As for the $50 \mathrm{~nm}$ nanoparticles, see Table S2, Figure S3).

a)

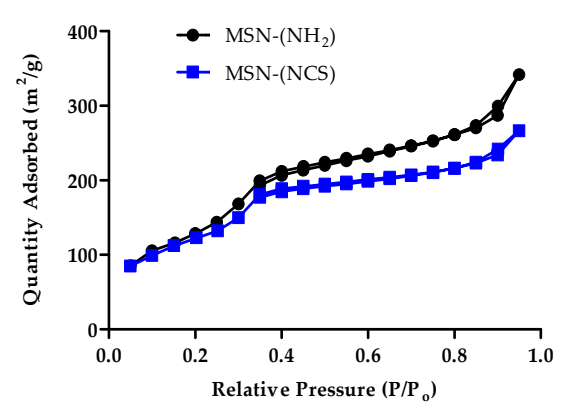

b)

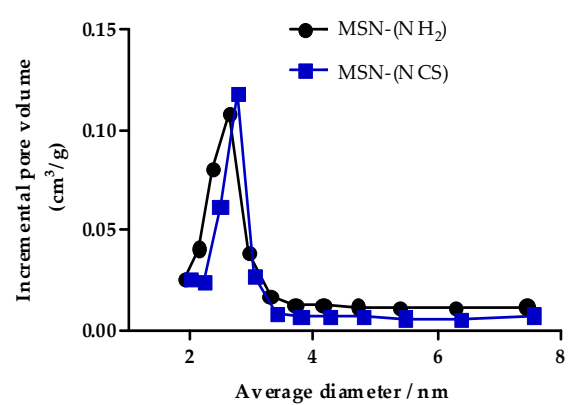

Figure 4. (a) Nitrogen adsorption-desorption isotherms of MSN-( $\left.\mathrm{NH}_{2}\right)$ and MSN-(NCS), (b) pore size distribution of MSN-( $\left.\mathrm{NH}_{2}\right)$ and MSN-(NCS) $(100 \mathrm{~nm})$. 
Furthermore, the successful functionalization of the MSNs is supported by the presence of two characteristic absorption bands around $2100 \mathrm{~cm}^{-1}$ in the FTIR spectrum ascribed to the isothiocyanate group (Figure 5).

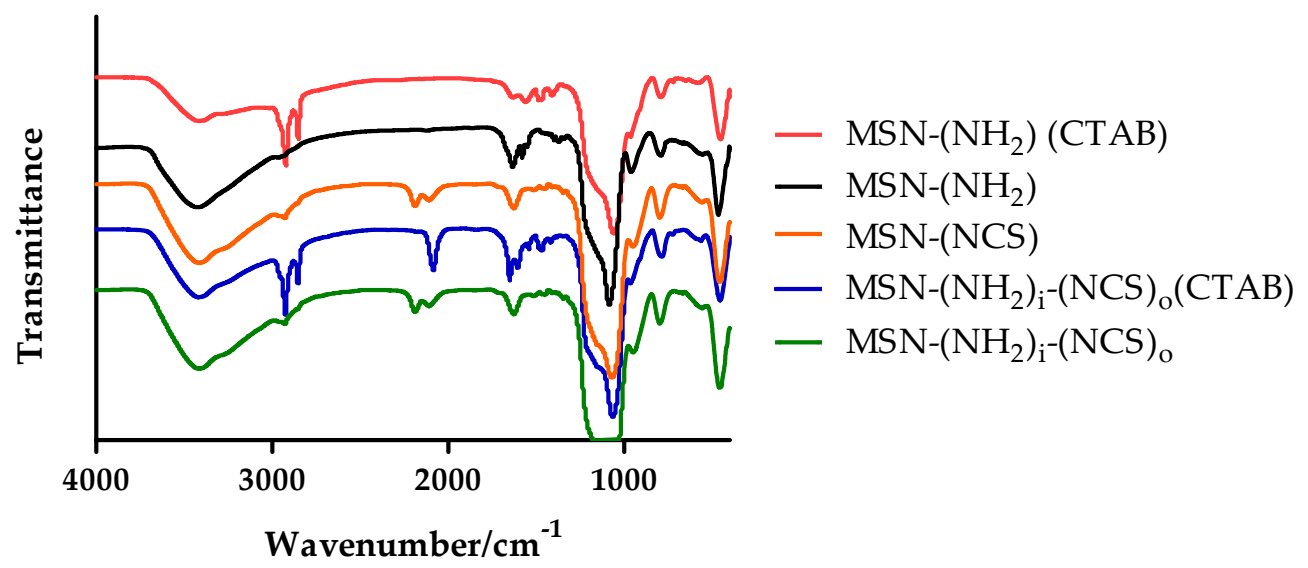

Figure 5. FTIR spectra of MSN-( $\left.\mathrm{NH}_{2}\right)(\mathrm{CTAB}), \mathrm{MSN}-\left(\mathrm{NH}_{2}\right), \mathrm{MSN}-(\mathrm{NCS}), \mathrm{MSN}-\left(\mathrm{NH}_{2}\right)_{\mathrm{i}}(\mathrm{NCS})_{\mathrm{o}}(\mathrm{CTAB})$, and $\mathrm{MSN}-\left(\mathrm{NH}_{2}\right)_{\mathrm{i}}(\mathrm{NCS})_{\mathrm{o}}$.

\subsection{Assessment of the Functionalization of MSN-(NCS)}

In order to test the functionalization of these new isothiocyanate MSNs, a fluorescent naphthalimide bearing an aliphatic primary amine was chosen. Then, 4-(n-butylamino)- $N$-(2-aminoethyl)-1,8naphthalimide (2) was synthetized from 1,8-bromonaphthalimide following a literature procedure [45]. Thus, the isothiocyanate-functionalized MSNs were exposed to the primary amine for $48 \mathrm{~h}$ using dichloromethane as a solvent to form MSN-(UNaph) (Figure S4). The reacting mixture was washed with the same solvent and centrifuged to render a yellow solid. The disappearance of the two bands around $2100 \mathrm{~cm}^{-1}$ (isothiocyanate group) indicates the completion of the reaction and the formation of the corresponding thiourea (Figure S5a).

To assess the performance of this new functionalization methodology, the CuAAC coupling was used as a standard [35,36]. Azido-(MSNs) were synthetized by functionalizing 3-azidopropionic acid succinimidyl ester (3) to the initial aminated MSNs (Figure S6). Furthermore, 3-azidopropionic acid succinimidyl ester (3) was synthetized from 3-bromopropionic acid following the literature [46]. Therefore, the corresponding azido-functionalized MSNs were coupled with a homologous napththalimide attached to a terminal alkyne to form MSN-(TNaph). Moreover, 4-(n-butylamino)- $N$-(2propargyl)-1,8-naphthalimide (4) was synthetized from 1,8-bromonaphthalimide following the literature [47]. The disappearance of the azido band around $2100 \mathrm{~cm}^{-1}$ indicated the completion of the reaction (Figure $\mathrm{S} 5 \mathrm{~b}$ ).

Both MSN-(NCS) and MSN- $\left(\mathrm{N}_{3}\right)$ nanoparticles were successfully functionalized with naphthalimide moieties presenting yellow coloration and a maximum band in the absorption spectrum of approximatively $450 \mathrm{~nm}$ (Figure S7). The functionalization capacity of both azido- and isothiocyanate MSNs (MSN-(NCS)) and (MSN-(N 3$)$ ) was determined by organic elemental analysis (OEA) (Table 1). To our delight, the loading turns out to be comparable in both cases $(4.6 \%$ when the CuAAC protocol was used, whereas the value was $4.8 \%$ for the new methodology).

As anticipated, these results confirm the suitability of the isothiocyanate group to participate in the functionalization of MSNs. The main difference in the protocols is the isolation of the nanoparticles. While the thiourea-containing MSNs are easily isolated, the removal of copper species from the $\mathrm{CuAAC}$ reaction requires tedious and extensive washings with solutions of chelating agents such as $\mathrm{Na}_{2}$ EDTA [37] or N,N-diethyldithiocarbamate [35]. 
Table 1. Organic elemental analysis (OEA) of MSN-(NCS), MSN-(UNaph), MSN-(N 3 ), and MSN-(TNaph).

\begin{tabular}{cccc}
\hline MSNs & C (\%) & H (\%) & N (\%) \\
\hline MSN-(NCS) & 9.78 & 1.87 & 1.92 \\
MSN-(UNaph) & 14.59 & 2.59 & 2.32 \\
MSN-(N $\left.{ }_{3}\right)$ & 7.22 & 2.56 & 2.64 \\
MSN-(TNaph) & 11.79 & 2.56 & 3.08 \\
\hline
\end{tabular}

\subsection{Synthesis and Characterization of Bifunctionalized Amino-Isothiocianate MSNs $\left(\mathrm{MSN}-\left(\mathrm{NH}_{2}\right)_{i}(\mathrm{NCS})_{0}\right)$}

Having validated the performance of the new isothiocyanate mono-functionalized MSNs, we were prompted to prepare regioselectively bifunctionalized amino-isothiocyanate MSNs adapting the previous protocol. Briefly, aminated MSNs (50 and $100 \mathrm{~nm}$ ) [44] containing the surfactant (CTAB) inside the pore were reacted with 12 eq. of 1,1'-thiocarbonyldi-2(1H)-pyridone (1) in dry toluene for $24 \mathrm{~h}$ (Figure 6). This solvent was carefully chosen in order to prevent the elimination of the surfactant. Then, the resulting solid was washed once with absolute ethanol and dry toluene.

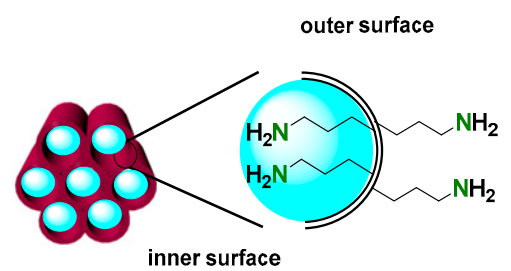

MSN-( $\left.\mathrm{NH}_{2}\right)_{\mathrm{i}}(\mathrm{CTAB})$

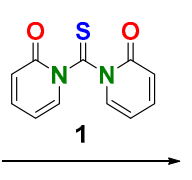

inner surface

MSN-( $\left.\mathrm{NH}_{2}\right)_{i}-(\mathrm{NCS})_{0}(\mathrm{CTAB})$

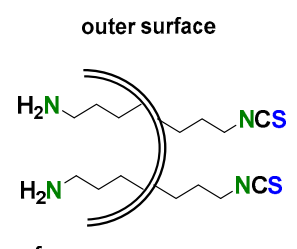

inner surface

MSN-(NH) - -(NCS)。

Figure 6. Regioselective synthesis of $\mathrm{MSN}-\left(\mathrm{NH}_{2}\right)_{\mathrm{i}}(\mathrm{NCS})_{\mathrm{o}}$.

At this stage, the FTIR spectrum of the MSNs confirms the successful introduction of the isothiocyanate moiety (absorption bands around $2100 \mathrm{~cm}^{-1}$ ) and the presence of the surfactant blocking the pore, which can be inferred from a typical absorption at $2990 \mathrm{~cm}^{-1}$ (C-H stretch) (Figure 5).

Additional proof of the occlusion of the pores is given by the BHJ porous size distribution (Figure 7a and Figure S8 and Table 2 and Table S3). Hence, the functionalization of the MSNs was carried out regioselectively in the outer surface thanks to the smooth conversion of amine groups into isothiocyanate by reagent (1), which does not disturb the surfactant.

a)

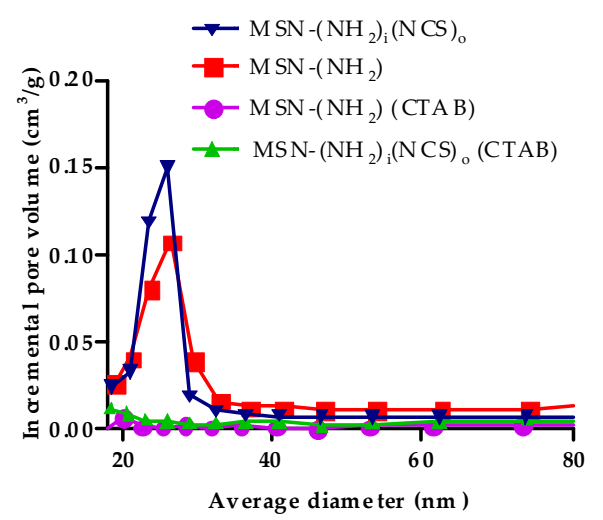

b)

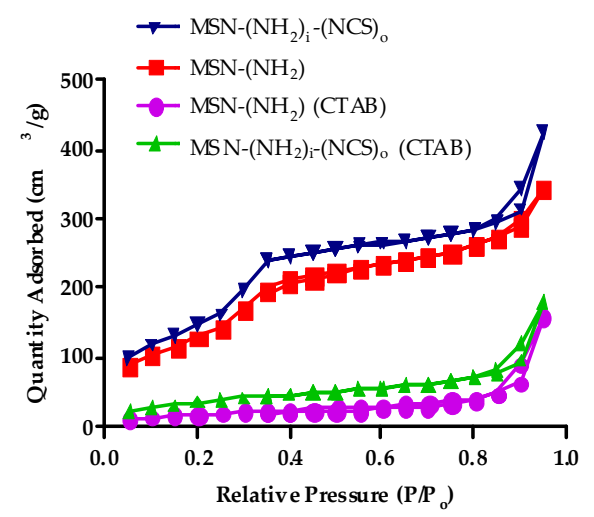

Figure 7. Characterization of regioselectively functionalized $\mathrm{MSN}-\left(\mathrm{NH}_{2}\right)_{\mathrm{i}}(\mathrm{NCS})_{\mathrm{o}}$. (a) Pore size distribution, (b) nitrogen adsorption-desorption isotherms $(100 \mathrm{~nm})$. 
Table 2. $\mathrm{N}_{2}$ adsorption-desorption (BET) and Barrett-Joyner-Halenda (BJH) pore size distribution values of MSN-( $\left.\mathrm{NH}_{2}\right)(\mathrm{CTAB}), \mathrm{MSN}-\left(\mathrm{NH}_{2}\right)$, and $\mathrm{MSN}-\left(\mathrm{NH}_{2}\right)_{\mathrm{i}}(\mathrm{NCS})_{\mathrm{o}}$ of $100 \mathrm{~nm}$.

\begin{tabular}{|c|c|c|c|}
\hline Property & MSN-( $\left.\mathrm{NH}_{2}\right)(\mathrm{CTAB})$ & $\mathrm{MSN}-\left(\mathrm{NH}_{2}\right)$ & $\mathrm{MSN}-\left(\mathrm{NH}_{2}\right)_{\mathrm{i}}(\mathrm{NCS})_{\mathrm{o}}$ \\
\hline BET surface area $\left(\mathrm{m}^{2} / \mathrm{g}\right)$ & 17.3 & 1120.90 & 1000.70 \\
\hline BJH pore volume $\left(\mathrm{cm}^{3} / \mathrm{g}\right)$ & 0.03 & 0.72 & 0.63 \\
\hline Pore size $(\mathrm{nm})$ & - & 2.20 & 2.20 \\
\hline
\end{tabular}

Finally, the surfactant was removed by treatment of the nanoparticles in a mixture $\mathrm{NH}_{4} \mathrm{NO}_{3}$ /methanol (treatment with $\mathrm{HCl} /$ methanol gives similar results). The complete removal of the template can be confirmed by comparing the change in the specific surface (Figure 7b).

The nanoparticles were characterized by the standard techniques. Again, as expected, no significant size, shape, and morphology differences were obtained for MSN- $\left(\mathrm{NH}_{2}\right)_{\mathrm{i}}(\mathrm{NCS})_{\mathrm{o}}$ in comparison with aminated MSNs. MSN-(NH$)_{i}(\mathrm{NCS})_{\mathrm{o}}$ are regular, homogeneous, and round shaped. As shown in Figure 8, spherical $100 \mathrm{~nm}$ nanoparticles with typical mesoporous morphology were obtained.

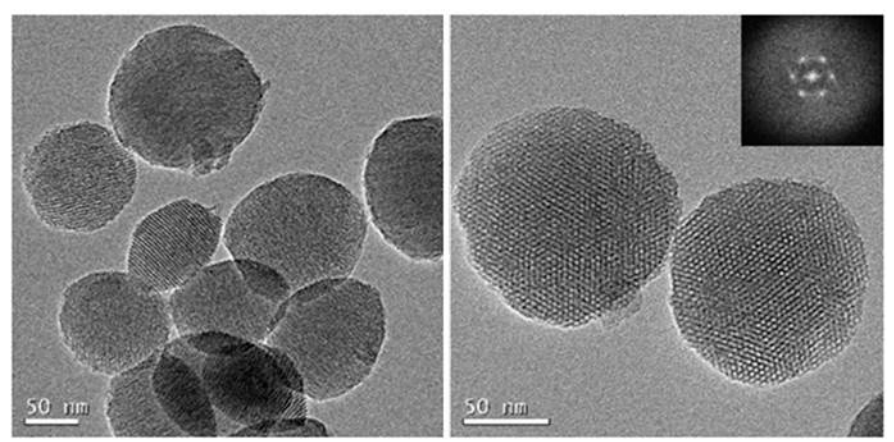

Figure 8. TEM images of MSN- $\left(\mathrm{NH}_{2}\right)_{\mathrm{i}}(\mathrm{NCS})_{\mathrm{o}}(100 \mathrm{~nm})$.

The particle size distribution was measured by dynamic light scattering (DLS) as shown in Figure S9 and Table S4 $(100 \mathrm{~nm})$, with the average particle size of $142(\mathrm{pdI}=0.07)$ and $173 \mathrm{~nm}(\mathrm{pdI}=0.04)$ for MSN- $\left(\mathrm{NH}_{2}\right)$ and MSN- $\left(\mathrm{NH}_{2}\right)_{\mathrm{i}}(\mathrm{NCS})_{\mathrm{o}}$, respectively. Z-potential was also measured with -12 and $-13 \mathrm{mV}$, respectively. Powder XRD patterns of MSN-(NCS) was also carried out. The small-angle $X$-ray diffraction (SAXRD) pattern presents highly ordered structures with d100 at 2.3 and lighter faceted hexagon-shape at 4.1 and 4.2 which indicated two-dimensional (2D) long-range ordering structure (Figure 3).

The $\mathrm{N}_{2}$ adsorption/desorption measurements for MSN- $\left(\mathrm{NH}_{2}\right)_{\mathrm{i}}(\mathrm{NCS})_{\mathrm{o}}$ showed type IV isotherms, which display clear H1 hysteresis loop characteristic of mesoporous materials (Figure 7a). For $100 \mathrm{~nm}$ nanoparticles, BET surface areas were over $1120 \mathrm{~m}^{2} \cdot \mathrm{g}^{-1}$ for $\mathrm{MSN}-\left(\mathrm{NH}_{2}\right)$, whereas those for MSN- $\left(\mathrm{NH}_{2}\right)_{\mathrm{i}}(\mathrm{NCS})_{\mathrm{o}}$ were $1000 \mathrm{~m}^{2} \cdot \mathrm{g}^{-1}$ Additionally, the pore volume for MSN- $\left(\mathrm{NH}_{2}\right)_{\mathrm{i}}(\mathrm{NCS})_{\mathrm{o}}$ was $0.63 \mathrm{~cm}^{3} \cdot \mathrm{g}^{-1}$. As a reference, the value recorded for MSN- $\left(\mathrm{NH}_{2}\right)$ was $0.72 \mathrm{~cm}^{3} \cdot \mathrm{g}^{-1}$. The MSNs present a very narrow pore size distribution centered at $2.2 \mathrm{~nm}$ (Table 2) (As for the $50 \mathrm{~nm}$ nanoparticles, see Tables S3 and S4, Figures S8-S10). Again, these nanoparticles are characterized by an excellent chemical stability and can be kept for about three months at room temperature $\left(23^{\circ} \mathrm{C}\right)$.

\subsection{Application of $\mathrm{MSN}-\left(\mathrm{NH}_{2}\right)_{i}(\mathrm{NCS})_{0}$ for the Preparation of a Nanocarrier for Ataluren Release}

The chemical stability of the MSN- $\left(\mathrm{NH}_{2}\right)_{\mathrm{i}}(\mathrm{NCS})_{\mathrm{o}}$ along with the clean reactivity and easy purification of the particles endows these systems with ideal properties to be used in the design of drug carriers as ready-to-use building blocks. The isothiocyanate groups located in the surface of the MSNs are amenable to react with a large variety of primary amines, ranging from simple alkyl amines, short PEGs to polymers. Once attached to the MSNs, their presence can modulate the release profile of the payload [13-16]. The chemical nature of these chains is a key factor to optimize not only the drug 
release but also the characteristics of the corona of the nanoparticles which define their biodistribution and clearance from the body [56]. Hence, a short and simple protocol to install such chemical valves from a large variety of commercially available amines can be of broad applicability.

As an application of this new methodology, a very simple nanocarrier for the delivery of Ataluren (Translarna ${ }^{\mathrm{TM}}$ ) [57] was designed. To this end, bifunctionalized amino-isothiocyanate nanoparticles $(50 \mathrm{~nm})$ were prepared (Figure 6). The presence of the amino groups in the inner surface of the porous is a key feature of the design, since it has been shown that amino groups enhance the loading and facilitates the release of carboxylic acid containing drugs [13-16].

Briefly, bifunctionalized MSN- $\left(\mathrm{NH}_{2}\right)_{\mathrm{i}}(\mathrm{NCS})_{\mathrm{o}}$ nanoparticles were loaded with the drug by exposing them to a solution of Ataluren in absolute ethanol or water as solvents. Then, the nanoparticles were reacted with a primary amine to seal the pores. Finally, the mixture was centrifuged and washed twice with ethanol. It is noteworthy that the only product present in the washing was the slight excess of the primary amine. Three amines were chosen: 1-(2-((2-aminoethyl)disulfanyl)ethyl)-3-(2,5,8,11,14,1, 20,23,26,29,32,35,38,41,44,47-hexadecaoxanonatetracontan-49-yl)thiourea (8), 3,6,9,12-Tetraoxatridecan1-amine (9) and (2-aminoethyl)trimethylammonium chloride (10) (Figure 9) [55].

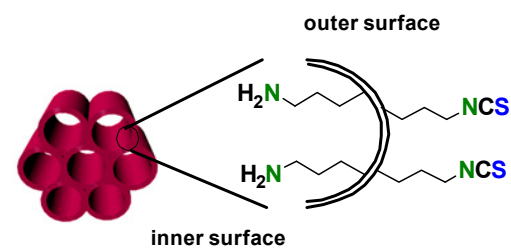

MSN-( $\left.\mathrm{NH}_{2}\right)_{\mathbf{i}}(\mathrm{NCS})$ 。
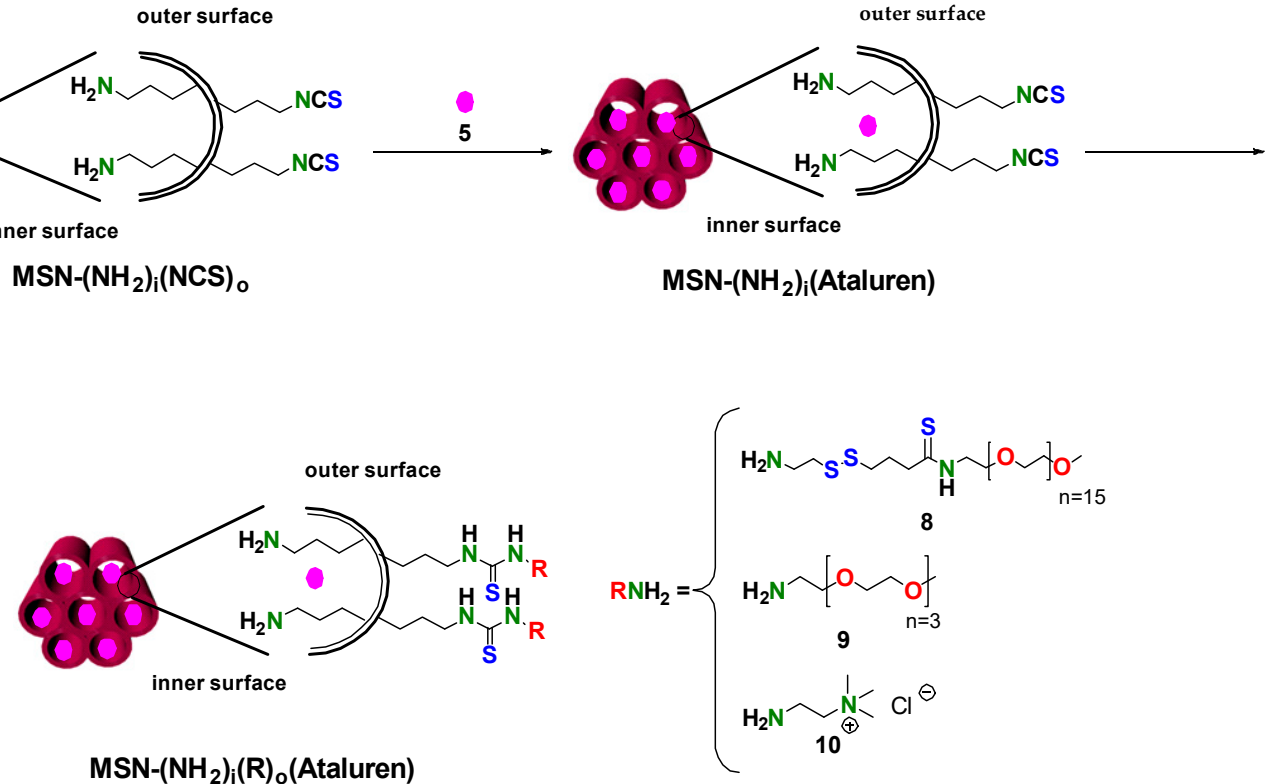

MSN-( $\left.\mathrm{NH}_{2}\right)_{\mathbf{i}}(\mathrm{R})_{\mathrm{o}}($ Ataluren)

Figure 9. Loading of $\mathrm{MSN}-\left(\mathrm{NH}_{2}\right)_{\mathrm{i}}(\mathrm{NCS})_{\mathrm{o}}$ with Ataluren and functionalization with 1-(2-((2aminoethyl)disulfanyl)ethyl)-3-(2,5,8,11,14,1,20,23,26,29,32,35,38,41,44,47-hexadecaoxanonatetracontan49-yl)thiourea (8), 3,6,9,12-tetraoxatridecan-1-amine (9) and (2-aminoethyl)trimethylammonium chloride (10).

The blocking effect of the amino-PEG (9) was clearly demonstrated by the release profile of Ataluren (Figure 10). Whereas for non-functionalized MSNs, Ataluren release was 52.7\%, for polyethylene glycol (9) MSNs (MSN- $\left(\mathrm{NH}_{2}\right)_{\mathrm{i}}(\mathrm{PEG})_{\mathrm{o}}$ (Ataluren)), the release was just $7.9 \%$, which clearly demonstrates the blocking effect of the PEG chain. A better obstruction of the pores can be achieved if the MSN is functionalized with a longer polyethylene glycol chain $(n=15)(8)\left(\mathrm{MSN}-\left(\mathrm{NH}_{2}\right)_{\mathrm{i}}(\mathrm{SS}-\mathrm{PEG})_{\mathrm{o}}\right.$ (Ataluren)) where only $4.1 \%$ of Ataluren was released. In the case of glycol (8), the PEG chain contains a labile disulfide bond, which under reductive conditions can be cleaved releasing the cargo, giving $22 \%$ of Ataluren (in a period of $6 \mathrm{~h}$ ). 


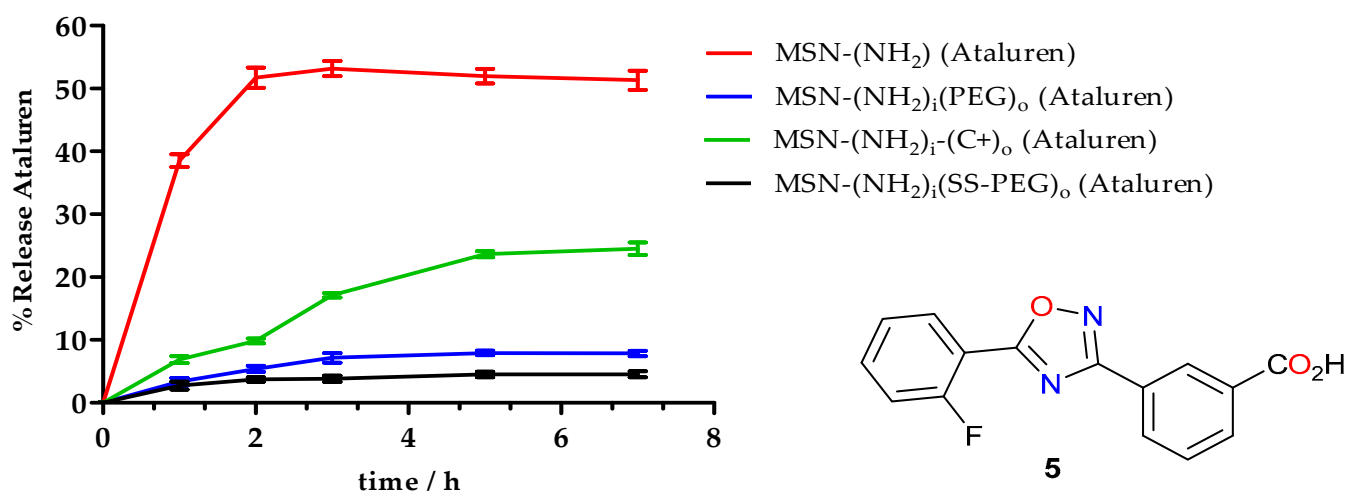

Figure 10. Release profile of Ataluren: Aminated nanoparticles ( $\mathrm{MSN}-\left(\mathrm{NH}_{2}\right)$ (Ataluren)), aminated nanoparticles functionalized with (2-aminoethyl)trimethylammonium (10) $\left(\mathrm{MSN}-\left(\mathrm{NH}_{2}\right)_{\mathrm{i}}\left(\mathrm{C}^{+}\right)_{\mathrm{o}}\right.$ (Ataluren)), aminated nanoparticles functionalized with polyethylene glycol (9) $\left(\mathrm{MSN}-\left(\mathrm{NH}_{2}\right)_{\mathrm{i}}(\mathrm{PEG})_{\mathrm{o}}\right.$ (Ataluren)), and aminated nanoparticles functionalized with polyethylene glycol disulfide bond (8) $\left(\mathrm{MSN}-\left(\mathrm{NH}_{2}\right)_{\mathrm{i}}(\mathrm{SS}-\mathrm{PEG})_{\mathrm{o}}(\right.$ Ataluren $)$ ).

However, since a slow and progressive release of the drug is recommended for its therapeutic use [58,59], a shorter amine was chosen. Thus, the PEG amine was substituted by (2-aminoethyl)trimethylammonium chloride (10). The aim of using a quaternized amine was to slow down the release of Ataluren by means of ionic interactions between the drug and the quaternary amine moiety. In this case, a softer and more controlled release of Ataluren was obtained (Figure 10). While for non-functionalized MSNs complete Ataluren release was obtained at $2 \mathrm{~h}$, for MSN- $\left(\mathrm{NH}_{2}\right)_{\mathrm{i}}\left(\mathrm{C}^{+}\right)_{\mathrm{o}}$ (Ataluren) the release profile was smoother providing $25.5 \%$ of Ataluren in a period of $6 \mathrm{~h}$.

\section{Conclusions}

In conclusion, a straightforward protocol to prepare isothiocyanate-functionalized MSNs has been described. The synthetic methodology is general and can be applied, in principle, to all types of aminated MSNs. The resulting MSNs are chemically stable and can be stored indefinitely. As anticipated, the particles easily react with primary amines and they are compatible with aqueous media. The efficiency of the functionalization is comparable to that of CuAAC. However, in stark contrast with the CuACC protocols, the isolation of the derivatized MSNs is simple and there is no need to remove any by-product or toxic catalysts. Furthermore, this methodology was applied to the regioselective synthesis of amino-isothiocyanate-functionalized MSNs. These nanoparticles have been used for the design of a nanocontainer able to release the drug Ataluren. The release profile of the drug can be fine-tuned with the careful choice of the capping amine. The application of such nanoparticles in the development of "smart" nanocarriers is currently ongoing in our laboratories.

Supplementary Materials: The following are available online at http://www.mdpi.com/2079-4991/9/9/1219/s1, Figure S1. Dynamic light scattering (DLS) size and Zeta-potential values of MSN-( $\left.\mathrm{NH}_{2}\right)$ and MSN-(NCS) of $50 \mathrm{~nm}(\mathrm{a}, \mathrm{b})$ and $100 \mathrm{~nm}(\mathrm{c}, \mathrm{d})$. Figure S2. Representative TEM images of $50 \mathrm{~nm}$ MSN-(NCS). Figure S3. $\mathrm{N}_{2}$ adsorption-desorption and BJH pore size distribution plots of $\mathrm{MSN}-\left(\mathrm{NH}_{2}\right)$ and MSN-(NCS) of $50 \mathrm{~nm}(\mathrm{a}, \mathrm{b})$. Figure S4. MSN-NCS functionalization with 4-(n-butylamino)- $N$-(2-aminoethyl)-1,8-naphthalimide. Figure S5. FTIR spectra of MSN-(NCS) (a) and MSN-(N $\left.\mathrm{N}_{3}\right)$ (b) reacted with 4-( $n$-butylamino)- $N$-(2-aminoethyl)-1,8-naphthalimide. Figure S6. MSN-( $\left.\mathrm{N}_{3}\right)$ functionalization with 4-(n-Butylamino)- $N$-(2-propargyl)-1,8-naphthalimide. Figure S7. Absorption spectra of MSN-(UNaph) and MSN-(TNaph). Figure S8. $\mathrm{N}_{2}$ adsorption-desorption surface area (a) and $\mathrm{BJH}$ pore size distribution plots (b) of MSN-(NH $)_{2}(\mathrm{CTAB}), \mathrm{MSN}-\left(\mathrm{NH}_{2}\right)$ and MSN- $\left(\mathrm{NH}_{2}\right)_{\mathrm{i}}(\mathrm{NCS})_{\mathrm{O}}$ of $50 \mathrm{~nm}$. Figure S9. Dynamic light scattering (DLS) size and Z-potential measures of MSN-( $\left.\mathrm{NH}_{2}\right)$ and $\mathrm{MSN}-\left(\mathrm{NH}_{2}\right)_{\mathrm{i}}(\mathrm{NCS})_{\mathrm{O}}$ of $50 \mathrm{~nm}(\mathrm{a}, \mathrm{b})$ and $100 \mathrm{~nm}(\mathrm{c}, \mathrm{d})$. Figure S10. TEM images of $50 \mathrm{~nm}$ MSN- $\left(\mathrm{NH}_{2}\right)_{\mathrm{i}}(\mathrm{NCS})_{\mathrm{o}}$. Table S1. Dynamic light scattering (DLS) size and Z-potential values of MSN-( $\left.\mathrm{NH}_{2}\right)$ and MSN-(NCS) of 50 and $100 \mathrm{~nm}$, Table S2. $\mathrm{N}_{2}$ adsorption-desorption and BJH pore size distribution values of MSN-( $\left.\mathrm{NH}_{2}\right)$ and MSN-(NCS) of $50 \mathrm{~nm}$, Table S3. $\mathrm{N}_{2}$ adsorption-desorption and BJH pore size distribution values of $\mathrm{MSN}-\left(\mathrm{NH}_{2}\right)(\mathrm{CTAB}), \mathrm{MSN}-\left(\mathrm{NH}_{2}\right)$ and MSN-( $\left.\mathrm{NH}_{2}\right)_{\mathrm{i}}(\mathrm{NCS})_{\mathrm{o}}$ of $50 \mathrm{~nm}$, Table S4. Dynamic light scattering (DLS) size and Z-potential values of MSN-( $\left.\mathrm{NH}_{2}\right)$ and MSN-( $\left.\mathrm{NH}_{2}\right)_{\mathrm{i}}(\mathrm{NCS})_{\mathrm{o}}$ of $50 \mathrm{~nm}$ and $100 \mathrm{~nm}$. Equation S1. \% Release Ataluren. 
Author Contributions: G.M.-E. and M.C.L. conceived and designed the experiments; G.M.-E. and M.C.L. performed the experiments; G.M.-E. and M.C.L. analyzed the data; D.S.-G. and S.B. wrote the paper.

Funding: This research received no external funding.

Acknowledgments: The authors acknowledge generous support from the "Asociación Duchenne Parent Project España". Fellowship by the "Institut Químic de Sarrià" (IQS) (G.M.-E. and M.C.L.) is gratefully acknowledged.

Conflicts of Interest: The authors declare no conflict of interest.

\section{References}

1. Vallet-Regí, M. Mesoporous Silica Nanoparticles: Their Projection in Nanomedicine. ISRN Mater. Sci. 2012, 2012, 1-20. [CrossRef]

2. Angelos, S.; Liong, M.; Choi, E.; Zink, J.I. Mesoporous silicate materials as substrates for molecular machines and drug delivery. Chem. Eng. J. 2008, 137, 4-13. [CrossRef]

3. Wang, Y.; Zhao, Q.; Han, N.; Bai, L.; Li, J.; Liu, J.; Che, E.; Hu, L.; Zhang, Q.; Jiang, T.; et al. Mesoporous silica nanoparticles in drug delivery and biomedical applications. Nanomed. Nanotechnol. Biol. Med. 2015, 11, 313-327. [CrossRef] [PubMed]

4. Mamaeva, V.; Sahlgren, C.; Lindén, M. Mesoporous silica nanoparticles in medicine-Recent advances. Adv. Drug Deliv. Rev. 2013, 65, 689-702. [CrossRef] [PubMed]

5. Vivero-Escoto, J.L.; Slowing, I.I.; Trewyn, B.G.; Lin, V.S.-Y. Mesoporous Silica Nanoparticles for Intracellular Controlled Drug Delivery. Small 2010, 6, 1952-1967. [CrossRef]

6. Ai, H.-W. Fluorescent Sensors for Biological Applications. Sensors 2014, 14, 17829-17831. [CrossRef] [PubMed]

7. Wolfbeis, O.S. An overview of nanoparticles commonly used in fluorescent bioimaging. Chem. Soc. Rev. 2015, 44, 4743-4768. [CrossRef]

8. Kempen, P.J.; Greasley, S.; Parker, K.A.; Campbell, J.C.; Chang, H.-Y.; Jones, J.R.; Sinclair, R.; Gambhir, S.S.; Jokerst, J.V. Theranostic Mesoporous Silica Nanoparticles Biodegrade after Pro-Survival Drug Delivery and Ultrasound/Magnetic Resonance Imaging of Stem Cells. Theranostics 2015, 5, 631-642. [CrossRef]

9. Knezevic, N.Z.; Mauriello Jimenez, C.; Albino, M.; Vukadinovic, A.; Mrakovic, A.; Illes, E.; Janackovic, D.; Durand, J.-O.; Sangregorio, C.; Peddis, D. Synthesis and Characterization of Core-Shell Magnetic Mesoporous Silica and Organosilica Nanostructures. MRS Adv. 2017, 2, 1037-1045. [CrossRef]

10. Song, N.; Yang, Y.-W. Molecular and supramolecular switches on mesoporous silica nanoparticles. Chem. Soc. Rev. 2015, 44, 3474-3504. [CrossRef]

11. Stein, A.; Melde, B.J.; Schroden, R.C. Hybrid Inorganic-Organic Mesoporous Silicates-Nanoscopic Reactors Coming of Age. Adv. Mater. 2000, 12, 1403-1419. [CrossRef]

12. Popat, A.; Hartono, S.B.; Stahr, F.; Liu, J.; Zhang Qiao, S.; Qing, G.; Lu, M. Mesoporous silica nanoparticles for bioadsorption, enzyme immobilisation, and delivery carriers. Nanoscale 2011, 3, 2801-2818. [CrossRef] [PubMed]

13. Muhammad, F.; Guo, M.; Qi, W.; Sun, F.; Wang, A.; Guo, Y.; Zhu, G. pH-Triggered Controlled Drug Release from Mesoporous Silica Nanoparticles via Intracelluar Dissolution of ZnO Nanolids. J. Am. Chem. Soc. 2011, 133, 8778-8781. [CrossRef] [PubMed]

14. Kamarudin, N.H.N.; Jalil, A.A.; Triwahyono, S.; Salleh, N.F.M.; Karim, A.H.; Mukti, R.R.; Hameed, B.H.; Ahmad, A. Role of 3-aminopropyltriethoxysilane in the preparation of mesoporous silica nanoparticles for ibuprofen delivery: Effect on physicochemical properties. Microporous Mesoporous Mater. 2013, 180, $235-241$. [CrossRef]

15. Natarajan, S.K.; Selvaraj, S. Mesoporous silica nanoparticles: Importance of surface modifications and its role in drug delivery. RSC Adv. 2014, 4, 14328. [CrossRef]

16. Wang, G.; Otuonye, A.N.; Blair, E.A.; Denton, K.; Tao, Z.; Asefa, T. Functionalized mesoporous materials for adsorption and release of different drug molecules: A comparative study. J. Solid State Chem. 2009, 182, 1649-1660. [CrossRef] 
17. Lee, C.-H.; Cheng, S.-H.; Huang, I.-P.; Souris, J.S.; Yang, C.-S.; Mou, C.-Y.; Lo, L.-W. Intracellular pH-Responsive Mesoporous Silica Nanoparticles for the Controlled Release of Anticancer Chemotherapeutics. Angew. Chem. Int. Ed. 2010, 49, 8214-8219. [CrossRef]

18. Li, Z.; Barnes, J.C.; Bosoy, A.; Stoddart, J.F.; Zink, J.I. Mesoporous silica nanoparticles in biomedical applications. Chem. Soc. Rev. 2012, 41, 2590. [CrossRef]

19. Rosenholm, J.; Sahlgren, C.; Lindén, M. Cancer-cell targeting and cell-specific delivery by mesoporous silica nanoparticles. J. Mater. Chem. 2010, 20, 2707. [CrossRef]

20. Ferris, D.P.; McGonigal, P.R.; Witus, L.S.; Kawaji, T.; Algaradah, M.M.; Alnajadah, A.R.; Nassar, M.S.; Stoddart, J.F. Oxime Ligation on the Surface of Mesoporous Silica Nanoparticles. Org. Lett. 2015, 17, 2146-2149. [CrossRef]

21. Thanh, N.T.K.; Green, L.A.W. Author's personal copy Functionalisation of nanoparticles for biomedical applications. Nano Today 2010, 5, 213-230. [CrossRef]

22. Wan, X.; Yao, S.; Liu, H.; Yao, Y. Selective fluorescence sensing of $\mathrm{Hg} 2+$ and $\mathrm{Zn} 2+$ ions through dual independent channels based on the site-specific functionalization of mesoporous silica nanoparticles. J. Mater. Chem. A 2013, 1, 10505. [CrossRef]

23. de Juan, F.; Ruiz-Hitzky, E. Selective Functionalization of Mesoporous Silica. Adv. Mater. 2000, 12, 430-432. [CrossRef]

24. Gao, J.; Wu, S.; Tan, F.; Tian, H.; Liu, J.; Lu, G.Q.M. Nanoengineering of amino-functionalized mesoporous silica nanospheres as nanoreactors. Prog. Nat. Sci. Mater. Int. 2018, 28, 242-245. [CrossRef]

25. Khung, Y.L.; Narducci, D. Surface modification strategies on mesoporous silica nanoparticles for anti-biofouling zwitterionic film grafting. Adv. Colloid Interface Sci. 2015, 226, 166-186. [CrossRef]

26. Miranda, F.S.; Ronconi, C.M.; Sousa, M.O.B.; Silveira, G.Q.; Vargas, M.D. 6-Aminocoumarin-Naphthoquinone Conjugates: Design, Synthesis, Photophysical and Electrochemical Properties and DFT Calculations. J. Braz. Chem. Soc. 2013, 25, 133-142. [CrossRef]

27. Huh, S.; Wiench, J.W.; Yoo, J.C.; Pruski, M.; Lin, V.S.Y. Organic Functionalization and Morphology Control of Mesoporous Silicas via a Co-Condensation Synthesis Method. Chem. Mater. 2003, 15, 4247-4256. [CrossRef]

28. Suteewong, T.; Sai, H.; Cohen, R.; Wang, S.; Bradbury, M.; Baird, B.; Gruner, S.M.; Wiesner, U. Highly Aminated Mesoporous Silica Nanoparticles with Cubic Pore Structure. J. Am. Chem. Soc. 2011, 133, 172-175. [CrossRef]

29. Kecht, J.; Schlossbauer, A.; Bein, T. Selective Functionalization of the Outer and Inner Surfaces in Mesoporous Silica Nanoparticles. Chem. Mater. 2008, 20, 7207-7214. [CrossRef]

30. Lallana, E.; Sousa-Herves, A.; Fernandez-Trillo, F.; Riguera, R.; Fernandez-Megia, E. Click Chemistry for Drug Delivery Nanosystems. Pharm. Res. 2012, 29, 1-34. [CrossRef]

31. Li, N.; Binder, W.H. Click-chemistry for nanoparticle-modification. J. Mater. Chem. 2011, 21, 16717. [CrossRef]

32. Pan, L.; He, Q.; Liu, J.; Chen, Y.; Ma, M.; Zhang, L.; Shi, J. Nuclear-Targeted Drug Delivery of TAT Peptide-Conjugated Monodisperse Mesoporous Silica Nanoparticles. J. Am. Chem. Soc. 2012, 134, 5722-5725. [CrossRef]

33. Doussineau, T.; Trupp, S.; Mohr, G.J. Ratiometric pH-nanosensors based on rhodamine-doped silica nanoparticles functionalized with a naphthalimide derivative. J. Colloid Interface Sci. 2009, 339, 266-270. [CrossRef] [PubMed]

34. Kotsuchibashi, Y.; Ebara, M.; Aoyagi, T.; Narain, R. Fabrication of doubly responsive polymer functionalized silica nanoparticles via a simple thiol-ene click chemistry. Polym. Chem. 2012, 3, 2545. [CrossRef]

35. Tian, Y.-Q.; Cai, C.-X.; Ren, X.-M.; Duan, C.-Y.; Xu, Y.; Gao, S.; You, X.-Z. The Silica-Like Extended Polymorphism of Cobalt(II) Imidazolate Three-Dimensional Frameworks: X-ray Single-Crystal Structures and Magnetic Properties. Chem. A Eur. J. 2003, 9, 5673-5685. [CrossRef]

36. Bolley, J.; Guenin, E.; Lievre, N.; Lecouvey, M.; Soussan, M.; Lalatonne, Y.; Motte, L. Carbodiimide versus Click Chemistry for Nanoparticle Surface Functionalization: A Comparative Study for the Elaboration of Multimodal Superparamagnetic Nanoparticles Targeting $\alpha_{\mathrm{v}} \beta_{3}$ Integrins. Langmuir 2013, 29, 14639-14647. [CrossRef] [PubMed] 
37. Malvi, B.; Sarkar, B.R.; Pati, D.; Mathew, R.; Ajithkumar, T.G.; Sen Gupta, S. “Clickable” SBA-15 mesoporous materials: Synthesis, characterization and their reaction with alkynes. J. Mater. Chem. 2009, 19, 1409. [CrossRef]

38. Radu, D.R.; Lai, C.Y.; Jeftinija, K.; Rowe, E.W.; Jeftinija, S.; Lin, V.S.Y. A Polyamidoamine Dendrimer-Capped Mesoporous Silica Nanosphere-Based Gene Transfection Reagent. J. Am. Chem. Soc. 2004. [CrossRef]

39. Zhang, Q.; Neoh, K.G.; Xu, L.; Lu, S.; Kang, E.T.; Mahendran, R.; Chiong, E. Functionalized Mesoporous Silica Nanoparticles with Mucoadhesive and Sustained Drug Release Properties for Potential Bladder Cancer Therapy. Langmuir 2014, 30, 6151-6161. [CrossRef]

40. El Malti, W.; Mongin, O.; Blanchard-Desce, M.; Raehm, L.; Durand, J.-O. Functionalisation of mesoporous silica nanoparticles with 3-isocynatopropyltrichlorosilane. Comptes Rendus Chim. 2011, 14, 1055-1058. [CrossRef]

41. Wiberg, K.B.; Wang, Y.; Miller, S.J.; Puchlopek, A.L.A.; Bailey, W.F.; Fair, J.D. Disparate Behavior of Carbonyl and Thiocarbonyl Compounds: Acyl Chlorides vs. Thiocarbonyl Chlorides and Isocyanates vs Isothiocyanates. J. Org. Chem. 2009, 74, 3659-3664. [CrossRef] [PubMed]

42. Hermanson, G.T. Bioconjugate Techniques; Academic Press: Cambridge, MA, USA, 2013.

43. Li, C.; Liu, J.; Alonso, S.; Li, F.; Zhang, Y. Upconversion nanoparticles for sensitive and in-depth detection of $\mathrm{Cu}^{2+}$ ions. Nanoscale 2012, 4, 6065. [CrossRef] [PubMed]

44. Cheng, S.-H.; Lee, C.-H.; Yang, C.-S.; Tseng, F.-G.; Mou, C.-Y.; Lo, L.-W. Mesoporous silica nanoparticles functionalized with an oxygen-sensing probe for cell photodynamic therapy: Potential cancer theranostics. J. Mater. Chem. 2009, 19, 1252. [CrossRef]

45. Grabchev, I.; Moneva, I.; Bojinov, V.; Guittonneau, S. Synthesis and properties of fluorescent 1,8-naphthalimide dyes for application in liquid crystal displays. J. Mater. Chem. 2000, 10, 1291-1296. [CrossRef]

46. Grandjean, C.; Boutonnier, A.; Guerreiro, C.; Fournier, J.-M.; Mulard, L.A. On the Preparation of Carbohydrate-Protein Conjugates Using the Traceless Staudinger Ligation. J. Org. Chem. 2005, 70, 7123-7132. [CrossRef] [PubMed]

47. Yum, J.-H.; Baranoff, E.; Wenger, S.; Nazeeruddin, M.K.; Gr, M. Panchromatic engineering for dye-sensitized solar cells. Energy Environ. 2011, 4, 842-857. [CrossRef]

48. Suga, Y.; Sunayama, H.; Ooya, T.; Takeuchi, T. Molecularly imprinted polymers prepared using protein-conjugated cleavable monomers followed by site-specific post-imprinting introduction of fluorescent reporter molecules. Chem. Commun. 2013, 49, 8450. [CrossRef]

49. Pei, J.; Wang, J.L.; Cao, X.Y.; Zhou, X.H.; Zhang, W.B. Star-Shaped Polycyclic Aromatics Based on Oligothiophene-Functionalized Truxene: Synthesis, Properties, and Facile Emissive Wavelength Tuning. J. Am. Chem. Soc. 2003. [CrossRef]

50. Li, G.; Bhosale, S.V.; Wang, T.; Hackbarth, S.; Roeder, B.; Siggel, U.; Fuhrhop, J.-H. Nanowells on Silica Particles in Water Containing Long-Distance Porphyrin Heterodimers. J. Am. Chem. Soc. 2003, 125, 10693-10702. [CrossRef]

51. Faure, A.-C.; Hoffmann, C.; Bazzi, R.; Goubard, F.; Pauthe, E.; Marquette, C.A.; Blum, L.J.; Perriat, P.; Roux, S.; Tillement., O. Functionalization of Luminescent Aminated Particles for Facile Bioconjugation. ACS Nano 2008, 2, 2273-2282. [CrossRef]

52. Wong, R.; Dolman, S.J. Isothiocyanates from Tosyl Chloride Mediated Decomposition of in Situ Generated Dithiocarbamic Acid Salts. J. Org. Chem. 2007, 72, 3969-3971. [CrossRef] [PubMed]

53. Sun, N.; Li, B.; Shao, J.; Mo, W.; Hu, B.; Shen, Z.; Hu, X. A general and facile one-pot process of isothiocyanates from amines under aqueous conditions. Beilstein J. Org. Chem. 2012, 8, 61-70. [CrossRef] [PubMed]

54. Harpp, D.N.; MacDonald, J.G.; Larsen, C. Utilization of thiocarbonyl transfer reagents. Preparation of thioamides, mercapto esters, and thiapyran derivatives. Can. J. Chem. 1985, 63, 951-957. [CrossRef]

55. Kim, S.; Yi, K.Y. 1,1'-Thiocarbonyldi-2,2'-pyridone. A new useful reagent for functional group conversions under essentially neutral conditions. J. Org. Chem. 1986, 51, 2613-2615. [CrossRef]

56. Ohno, K.; Akashi, T.; Tsujii, Y.; Yamamoto, M.; Tabata, Y. Blood Clearance and Biodistribution of Polymer Brush-Afforded Silica Particles Prepared by Surface-Initiated Living Radical Polymerization. Biomacromolecules 2012, 13, 927-936. [CrossRef]

57. Department of Reproductive Health World Health Organization. Medical Eligibility Criteria for Contraceptive Use, 4th ed.; WHO: Geneva, Switzerland, 2010; pp. 1-130. 
58. Bibee, K.P.; Cheng, Y.-J.; Ching, J.K.; Marsh, J.N.; Li, A.J.; Keeling, R.M.; Connolly, A.M.; Golumbek, P.T.; Myerson, J.W.; Hu, G.; et al. Rapamycin nanoparticles target defective autophagy in muscular dystrophy to enhance both strength and cardiac function. FASEB J. 2014, 28, 2047-2061. [CrossRef]

59. Vallet-Regí, M.; Balas, F.; Arcos, D. Mesoporous Materials for Drug Delivery. Angew. Chemie Int. Ed. 2007, 46, 7548-7558. [CrossRef]

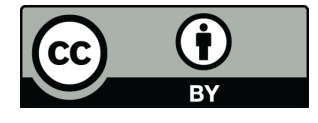

(C) 2019 by the authors. Licensee MDPI, Basel, Switzerland. This article is an open access article distributed under the terms and conditions of the Creative Commons Attribution (CC BY) license (http://creativecommons.org/licenses/by/4.0/). 